\title{
Parietal and occipital lobe contributions to perception of straight ahead orientation
}

\author{
Susanne Ferber, Hans-Otto Karnath
}

\begin{abstract}
Objectives-Several studies have investigated how peripheral stimulation affects the perception of body orientation in healthy subjects. The studies showed that opposing stimulation of two different input modalities can cancel out, leaving perception of body orientation unchanged. It was ascertained whether a comparable phenomenon could be found in brain damaged patients with two distinct disorders which individually lead to opposing shifts of the perceived midline.

Methods-The visual subjective straight ahead was measured in patients with pure neglect, pure hemianopia, or a combination of neglect and hemianopia.

Results-As in previous studies, patients with pure neglect displayed an ipsilesional displacement of the perceived straight ahead. Patients with pure hemianopia showed a contralesional shift. By contrast, no significant midline shift occurred in the patients with both neglect and hemianopia.

Conclusions-Neglect and hemianopia interact so that opposing biases in the perception of body orientation neutralise each other. Both parietal and occipital areas seem to contribute to the perception of straight ahead body orientation and seem to have counteracting effects when lesioned in the same hemisphere.

(F Neurol Neurosurg Psychiatry 1999;67:572-578)
\end{abstract}

Keywords: subjective straight ahead; spatial neglect; hemianopia; brain damage

One index of perceived body orientation in the horizontal plane is the subjective straight ahead (SSA). In normal subjects, straight ahead judgements are closely scattered around the body midsagittal plane and thus coincide fairly well with the objective body position. ${ }^{12}$ Several studies have examined the contribution of different input channels to the perception of the SSA in healthy subjects. Early reports showed that objective and apparent orientation of the median plane can be experimentally dissociated. Stimulating the semicircular canals by rotatory acceleration shifts the SSA in the direction opposite to the rotation. ${ }^{34}$ Caloric stimulation of one labyrinth with ice water moves the SSA towards the colder ear. ${ }^{5}$

Comparable results are achieved by modulating vision or neck proprioception in healthy subjects. Vibration of posterior neck muscles shifts the SSA towards the side of stimulation. ${ }^{67}$ Optokinetic stimulation similarly influences the perception of straight ahead body orientation. With increasing velocity of an optokinetic drum, the SSA deviated progressively in the direction of the movement, up to a maximum displacement of almost $10^{\circ}$ at a drum speed of about $80 \% \mathrm{~s}^{4}$

Simultaneous manipulation of two different input modalities counteracts or intensifies their individual effects. Karnath et al showed that combining both vestibular stimulation and neck muscle vibration led to an additive effect: Caloric ice water stimulation and neck muscle vibration on the same side of the body resulted in a displacement of doubled intensity, whereas vestibular stimulation on the left and proprioceptive stimulation on the right neutralised the effects that the inputs had when applied separately.

These results indicate that visual, vestibular, and neck proprioceptive input are integrated into a neural representation of space for perception of body orientation. A major centre for this integration seems to be the parietal cortex. Neurons in the parietoinsular vestibular cortex (PIVC) respond to all three (visual, vestibular, and neck proprioceptive) input modalities. ${ }^{89}$ Therefore, it seems likely that lesions in the parietal cortex should result in a disturbed perception of body orientation. In fact, it has been reported that patients with neglect, which is typically induced by right inferior parietal lesions, show a rightward displacement of the SSA. ${ }^{10-18}$ Moreover, a deviation of the SSA has also been found in patients with optic ataxia after lesions of the superior parietal lobe. ${ }^{16}$

However, deviations of the perceived straight ahead body orientation are not restricted to lesions of the parietal cortex. Lesions of the occipital lobe leading to primary visual field defects such as hemianopia have long been known to influence the perception of space. Early reports showed that patients with hemianopia usually show a contralesional displacement in line bisection tasks. ${ }^{19-23}$ Moreover, Best $^{24}$ showed that these patients also make errors in pointing tasks. When asked to point to targets that appear in front of them, they systematically erred toward the blind hemifield. The author interpreted this finding in terms of a displacement of the SSA towards the affected hemifield. A similar view was put forward by Fuchs, ${ }^{24}$ who suggested that the centre of the remaining visual field is subjectively shifted in a contralesional direction and serves as a so called "pseudofovea", which constitutes the new centre of the spatial reference frame in which objects are localised. Best ${ }^{25}$ reported the first evidence for a relation between the location of the scotoma and the direction of the line bisection shift, even in the vertical plane. 
Demographic and clinical data for the patients with pure left sided neglect (NEG), pure left sided hemianopia (HA), and left sided neglect and hemianopia $(N E G+H A)$

\begin{tabular}{|c|c|c|c|c|c|c|c|c|c|c|c|}
\hline \multirow[b]{2}{*}{ Patient } & \multirow[b]{2}{*}{ Sex } & \multirow[b]{2}{*}{ Age (y) } & \multirow[b]{2}{*}{ Aetiology } & \multirow{2}{*}{$\begin{array}{l}\text { Days after } \\
\text { onset }\end{array}$} & \multicolumn{2}{|c|}{ Letter cancellation } & \multicolumn{2}{|c|}{ Baking tray task } & \multicolumn{2}{|c|}{ Copying } & \multirow{2}{*}{$\begin{array}{l}\text { Picture } \\
\text { comparison }\end{array}$} \\
\hline & & & & & Left & Right & Left & Right & Left & Right & \\
\hline NEG1 & M & 63 & Infarct & 11 & 0 & 20 & NA & & - & - & NA \\
\hline NEG2 & M & 66 & Infarct & 7 & 14 & 25 & 0 & 16 & + & + & NA \\
\hline NEG3 & $\mathrm{F}$ & 50 & Infarct & 144 & 1 & 24 & 7 & 9 & $(-)$ & $(-)$ & NA \\
\hline NEG4 & M & 64 & Infarct & 2 & 12 & 25 & 10 & 6 & - & + & 3 \\
\hline NEG5 & $\mathrm{F}$ & 69 & Infarct & 11 & 0 & 23 & 5 & 11 & + & + & 0 \\
\hline NEG6 & M & 48 & Haemorrhage & 130 & 19 & 30 & 6 & 10 & - & + & 0 \\
\hline HA1 & M & 39 & Infarct & 250 & 30 & 29 & NA & & NA & & 0 \\
\hline HA2 & M & 60 & Infarct & 140 & 30 & 30 & 8 & 8 & NA & & 0 \\
\hline HA3 & $\mathrm{F}$ & 75 & Infarct & 5 & 20 & 25 & 8 & 8 & NA & & 0 \\
\hline NEG+HA1 & M & 46 & Haemorrhage & 42 & 9 & 30 & 8 & 8 & - & + & 2 \\
\hline NEG+HA2 & $\mathrm{F}$ & 62 & Infarct & 12 & 0 & 15 & 2 & 14 & - & $(-)$ & 3 \\
\hline NEG+HA3 & M & 69 & Infarct & 23 & 0 & 8 & 4 & 12 & - & $(-)$ & 3 \\
\hline NEG+HA4 & M & 69 & Haemorrhage & 25 & 0 & 16 & 6 & 10 & - & - & 2 \\
\hline NEG+HA5 & $\mathrm{F}$ & 79 & Infarct & 4 & 0 & 10 & 0 & 16 & - & $(-)$ & 3 \\
\hline
\end{tabular}

Picture comparison ${ }^{33}$ : three vertically aligned pairs of drawings with left sided differences and three pairs of drawings with right sided differences were presented on a horizontally oriented DIN A4 sheet. Each neglected left sided but detected right sided difference was scored as one $\left(\mathrm{n}_{\max }=3\right)$. Baking tray task ${ }^{34}$ : patients have to place 16 identical items as evenly as possible on a test sheet (DIN A 4). Reported is the number of items distributed within each half of the sheet. Letter cancellation ${ }^{35}$ : number of detected target letters on each half of the test sheet $\left(\mathrm{n}_{\mathrm{max}}=30\right.$ on either side). Copying task: the patients were asked to copy a complex multiobject scene consisting of four elements (a fence, a car, a house, and a tree) two in each half of a horizontally oriented DIN A4 paper: $-=$ omission of at least one whole object; $(-)$, omission of at least one left sided feature of a figure; += copying without omissions; NA=task not administered.

Recently, Kerkhoff ${ }^{26}$ analysed this issue systematically and confirmed Best's finding. Further, Zihl and von Cramon ${ }^{27}$ found that patients with hemianopia due to infarction in the territory of the posterior cerebral artery underestimated horizontal spatial distances in the affected hemifield and overestimated them in the intact hemifield. On the basis of these perceptual distortions in both hemifields, the authors calculated a new subjective midpoint of space. This calculated straight ahead position was displaced towards the affected hemifield, much like the subjective straight ahead measured by Best $^{25}$ and Kerkhoff. ${ }^{26}$

The previous studies left unclear how lesions causing a primary visual field defect (as hemianopia) and a distortion of space representation (as spatial neglect) interact concerning the perception of straight ahead orientation. It has been shown that manipulating two input modalities (for example, neck proprioceptive and vestibular input) intensifies or counteracts the effects of manipulating them separately. ${ }^{7}$ On this basis, it may be argued that damage in two anatomically separated cortical areas both involved in the perception of body orientation may interact so that the specific effect of damage in only one of these two regions is cancelled out or intensified.

We tested this idea by measuring the SSA in patients with pure neglect, pure hemianopia, or a combination of neglect and hemianopia. In line with previous findings, we expected to find a contralesional shift of the SSA in patients with hemianopia and an ipsilesional shift in neglect patients. The interesting question was how the SSA perception is affected in patients who have both disorders-neglect and hemianopia-resulting from lesions in the same hemisphere. If the primary visual field defect and the disturbance of space representation interact like counteracting inputs from different peripheral organs (visual, vestibular, and neck proprioceptive system), we would expect to find a neutralisation of SSA deviation - that is, a realignment of subjective and objective body orientation.

\section{Methods}

SUBJECTS

Twenty four subjects gave their informed consent to participate in the study. To compare the selective effects of neglect and hemianopia on the perception of straight ahead, only patients with hemianopia after infarction in the territory of the posterior cerebral artery were included. A lesion in the territory of this artery is unlikely to evoke even subtle hemispatial neglect that might be missed by clinical neglect tests.

Participating in the study were six patients with pure left sided neglect, three with pure left sided hemianopia, and five with both left sided neglect and hemianopia. Only patients with complete homonymous hemianopia were included. Demographic and clinical data of the patients are shown in the table. Figure 1 illustrates the lesions of patients with pure neglect; figure 2 presents the lesions of the patients with neglect and hemianopia and the patients with pure hemianopia. Subjects' visual fields were measured by means of the Tübingen perimeter.

Control subjects were five patients with unilateral right sided brain damage but no signs of neglect, hemianopia, or other visual field defects (one woman, four men, median age 59 years) and five non-brain damaged neurological patients (two women, three men, median age 52 years).

\section{APPARATUS AND PROCEDURE}

The experiment was conducted in complete darkness. Subjects sat upright in an armchair, head and body axes aligned. The head was fixed with a bandage to a head rest and was also held stable by an experimenter. Two parallel, horizontal guide rails were mounted $120 \mathrm{~cm}$ and $300 \mathrm{~cm}$ away from the subjects at eye level (figs 3 and 4). On each guide rail was a single movable red light emitting diode (LED). Each trial started with one LED illuminated at a random location left or right of the subjects' midsagittal plane, at either the near or the far distance. The LED appeared between $20^{\circ}$ and $40^{\circ}$ to the right or to the left of the subject's objective midsagittal plane, which was aligned 
NEG1

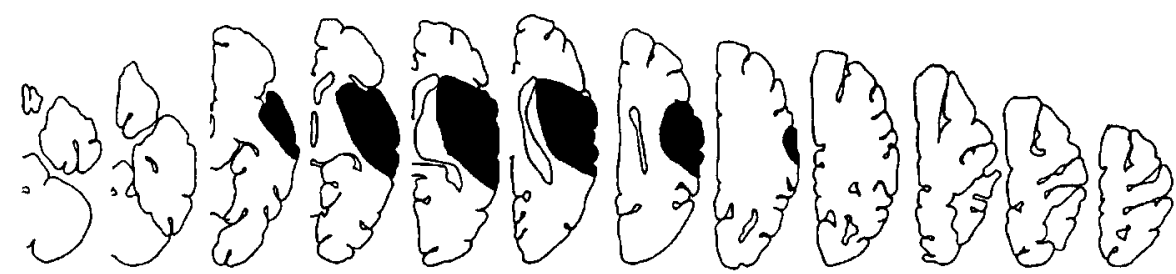

NEG2

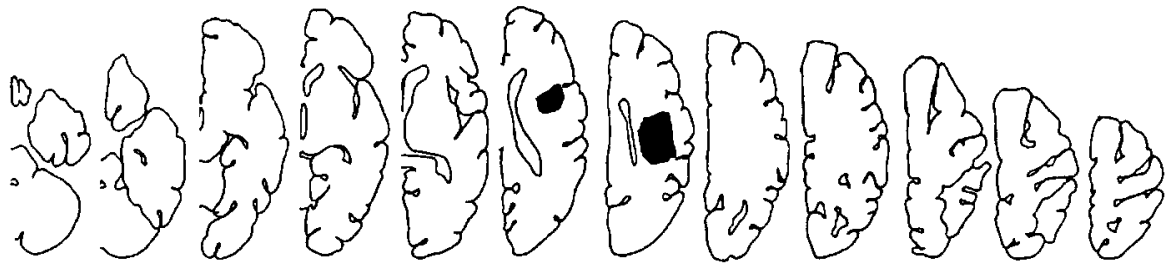

NEG3

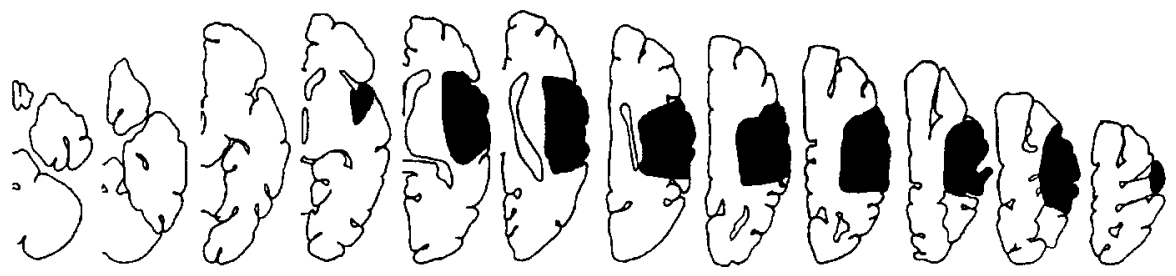

NEG4

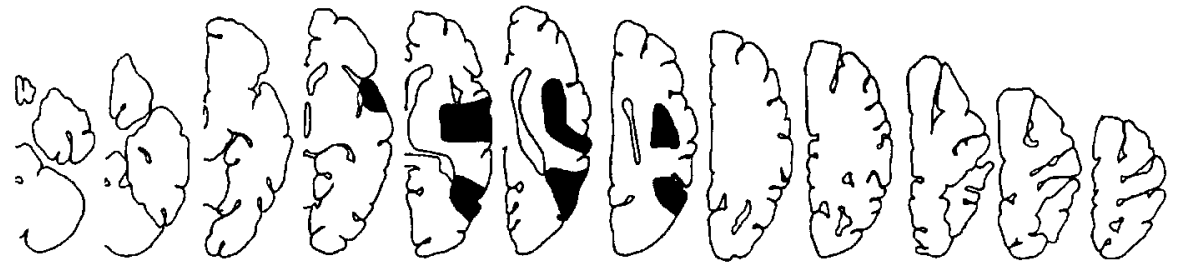

NEG5

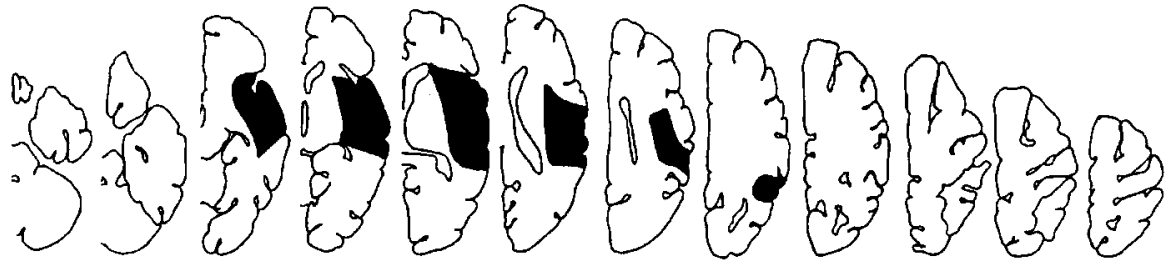

NEG6

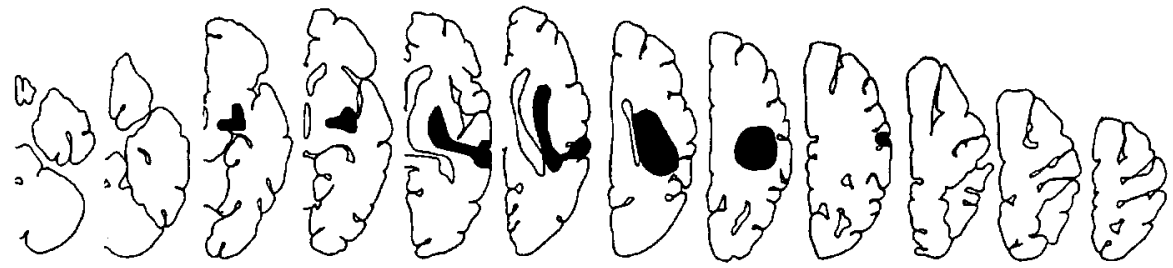

Figure 1 Lesioned areas in the patients with pure left sided neglect (NEG). The reconstructions are based on CT or MRI according to the technique described by Damasio and Damasio. ${ }^{36}$

with LED position $0^{\circ}$. The subjects' task was to direct the LED to a position which they thought lay exactly straight ahead of their bodies. Because confounding influences of possible visuomotor impairments on the judgements should be ruled out, we asked the subjects to direct the LED by verbal commands. One experimenter moved the LED in a stop and go procedure according to the subject's instructions. Twelve trials of straight ahead judgements were run at each distance (near, far) in an alternating order. For data analysis, judgements at both distances were averaged separately.

\section{Results}

Neither the non-brain damaged subjects nor the patients with right hemispheric damage but without neglect or visual field defect displayed an apparent shift of the perceived body midline. Their judgements of the SSA were close to the objective position of the midsagittal plane (fig 3). The subjects without brain damage directed the LED at the near distance to an average position of $0.3^{\circ} \mathrm{left}\left(\mathrm{SD} 0.5^{\circ}\right)$ and at the far distance of $0.5^{\circ}$ left $\left(\mathrm{SD} 0.8^{\circ}\right)$. The right brain damaged control subjects placed the near LED $1.0^{\circ}$ left (SD $1.9^{\circ}$ ) of the true straight ahead and the far LED $0.8^{\circ}$ left (SD $\left.1.1^{\circ}\right)$.

By contrast with controls, patients with left sided hemianopia showed a displacement of midline localisation towards the contralesional side which was $8.2^{\circ}$ left $\left(\mathrm{SD} 5.5^{\circ}\right)$ at the near distance and $8.1^{\circ}$ left (SD $3.1^{\circ}$ ) at the far distance. Neglect patients on the other hand 
HA1

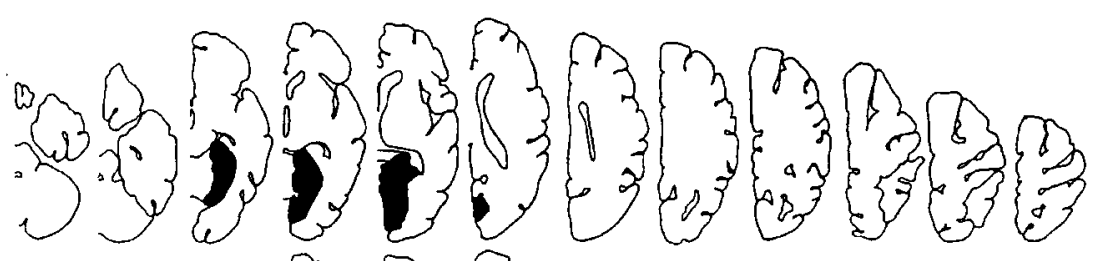

HA2

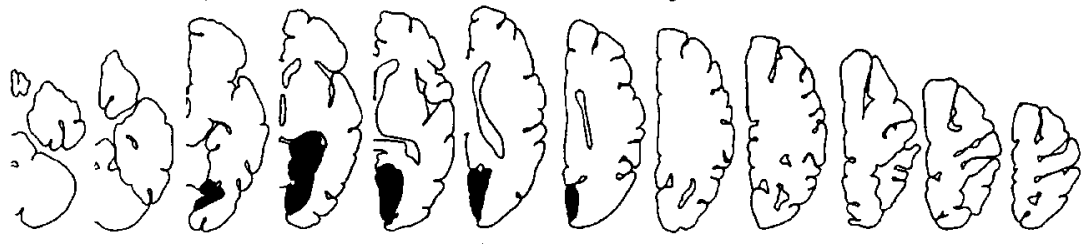

HA3

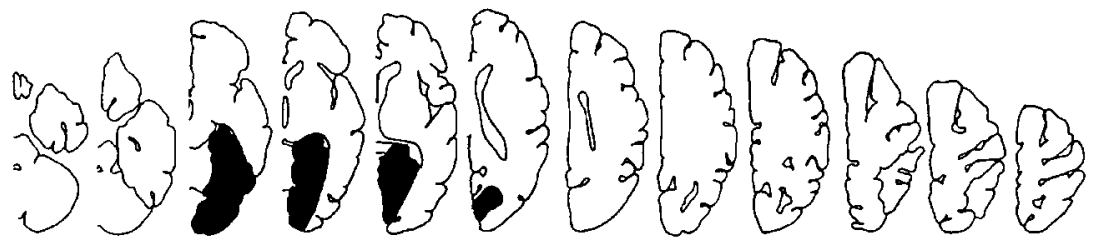

NEG + HA1

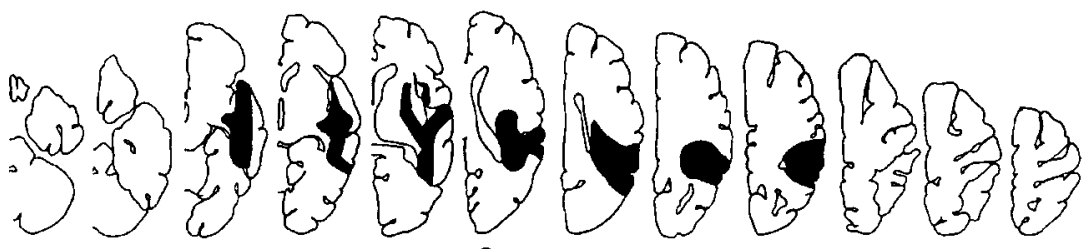

$\mathrm{NEG}+\mathrm{HA} 2$
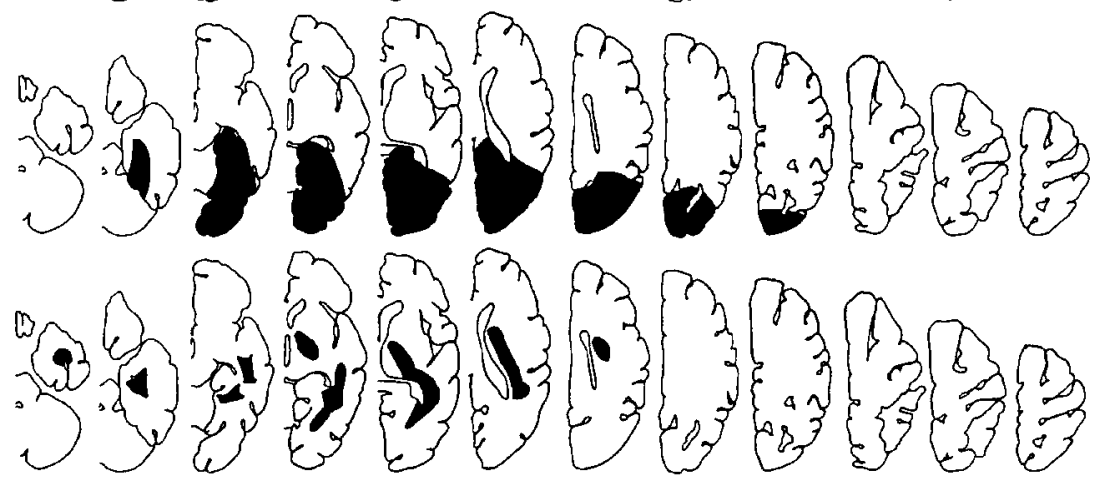

$\mathrm{NEG}+\mathrm{HA} 4$
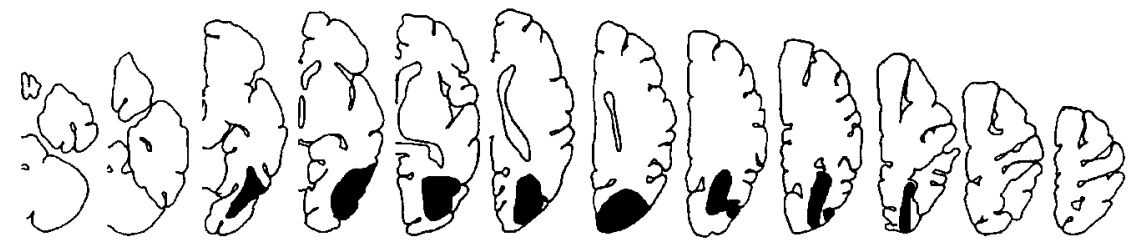

$N E G+H A 5$
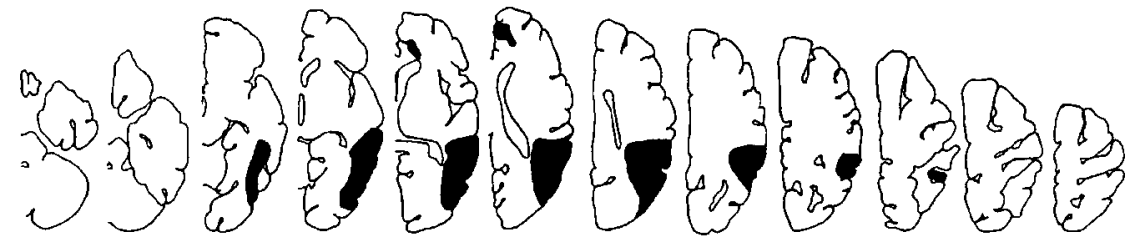

Figure 2 Lesioned areas in the patients with both left sided neglect and hemianopia (NEG+HA) and in the patients with pure left sided hemianopia (HA) due to infarction in the territory of the posterior cerebral artery.

perceived their bodies to be oriented towards the opposite direction, the ipsilesional side (fig 4). They misplaced the near LED $5.1^{\circ}$ right (SD $1.7^{\circ}$ ) and the far LED $4.1^{\circ}$ right (SD $\left.4.0^{\circ}\right)$. Patients with both neglect and hemianopia showed much smaller errors, directing the near LED to an average position of $1.3^{\circ}$ left (SD $1.5^{\circ}$ ) and the far LED to an average position of $1.1^{\circ}$ left $\left(\mathrm{SD} 2.0^{\circ}\right)$.
Because of heterogeneous variance in our data (Levene test, $\mathrm{p}=0.02$ ), we employed nonparametric tests for further analysis. As there was no significant effect of near and far distance on SSA perception (Wilcoxon matched pairs test, $\mathrm{p}=0.689$ ), judgements at both distances were combined for each group. Further, as there were no differences between non-brain damaged and right brain damaged 


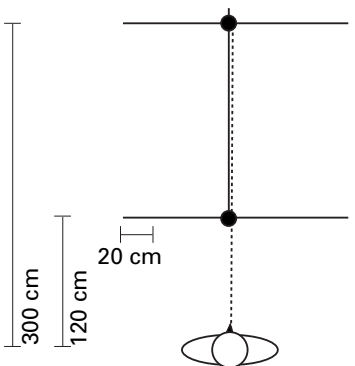

Non-brain damaged controls

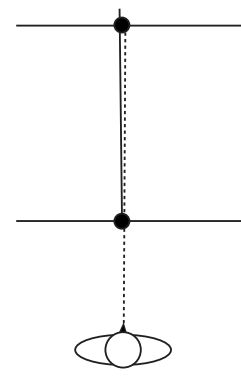

Right brain damaged controls
Figure 3 Subjective straight ahead in non-brain damaged and in right brain damaged control subjects. The subjects are illustrated as seen from above. The dotted line is the physical midsagittal plane. The filled circles represent the average subjective straight ahead position of the red LED, which was presented at either of two different distances $(120 \mathrm{~cm}$ or $300 \mathrm{~cm})$. The bold line connecting the circles illustrates the perceived orientation of the midsagittal plane.

control subjects ( $U=0.347)$, data of both groups were combined and termed "controls" in the following.

The four groups (neglect, hemianopia, neglect + hemianopia, controls) were compared by a Kruskal-Wallis $H$ test. A significant difference between subject groups was found $\left(\chi^{2}=17.23 ; \mathrm{p}<0.001\right)$. Based on previous studies (see introduction), hypotheses for the comparisons between controls versus neglect patients, controls versus patients with hemianopia, and neglect patients versus hemianopic patients were clear. We expected an ipsilesional shift in patients with neglect and a contralesional shift in patients with hemianopia. Thus, one tailed post hoc $U$ tests were used to compare these groups. Two tailed post hoc $U$ tests were used to compare patients with both neglect and hemianopia and the three other groups (neglect, hemianopia, controls). Bonferroni-Holm correction was applied to all six post hoc $U$ tests.

The tests disclosed significant differences between controls and neglect patients $(p<0.001)$, between controls and patients with hemianopia $(\mathrm{p}=0.004)$, between neglect patients and hemianopic patients $(p=0.01)$ and neglect patients and patients with both neglect and hemianopia $(\mathrm{p}=0.004)$. All other comparisons failed to reach significance. In particular, there was no significant difference between controls and patients with both syndromes, neglect and hemianopia $(\mathrm{p}=0.514)$.

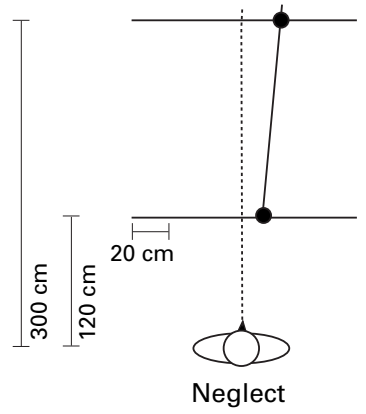

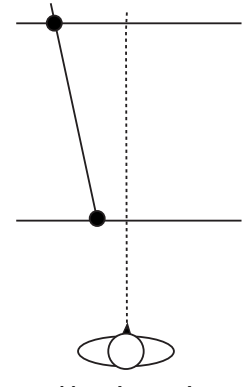

Hemianopia

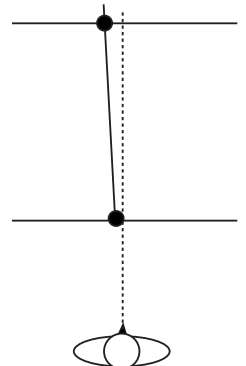

Neglect and hemianopia
Figure 4 Subjective straight ahead in patients with neglect, patients with pure hemianopia, and patients with both neglect and hemianopia. Symbols are as in fig 3.

\section{Discussion}

As in previous studies, ${ }^{10-18}$ patients with pure neglect displayed an ipsilesional shift of the subjective straight ahead. By contrast, patients with pure hemianopia showed a contralesional shift. This finding accords with reports of a rightward shift in line bisection tasks in hemianopic patients. ${ }^{19-23}$ Because our testing procedure involved no motor response, the results cannot be accounted for by motor disturbances such as directional hypokinesia or optic ataxia.

The main finding of the present study was that the patients with both neglect and hemianopia displayed no significant shift of midline localisation. Previous studies have shown that opposing manipulation of two different input channels contributing to the perception of body orientation neutralised their individual effects. ${ }^{4}$ The present results show that the same holds true for ipsilateral cortical lesions leading to two distinct syndromes: spatial neglect and hemianopia. Although neglect and hemianopia individually lead to a marked opposing deviation of the SSA, a combination of both syndromes can leave the SSA in line with the physical midline. The opposing effects on SSA perception seem to cancel each other out.

This cancellation may account for recent findings reporting an absence of a midline shift in some neglect patients. ${ }^{28}$ Three patients with neglect but without extensive parietal lobe damage showed no deviation of the perceived straight ahead position. By contrast, two further patients with neglect and parietal lobe damage displaced the SSA. The authors concluded that the presence of a midline shift is due to extensive parietal lobe damage rather than to neglect. Although their argument is convincing, a possible confounding factor cannot be ruled out as influencing midline judgements in their study at least in one patient. This patient had both left sided neglect and left sided hemianopia. In the light of the present results it seems likely that this patient displayed no midline shift because neglect and hemianopia had opposing effects on the patient's SSA perception.

Our results seem to conflict with the recent finding by Farnè $e t ~ a l^{17}$ that patients with both neglect and hemianopia showed a marked deviation of the SSA towards the ipsilesional side. Moreover, these authors found no significant contralesional displacement of the SSA in patients with pure hemianopia. At least this second finding contrasts with all previous studies that investigated SSA perception in patients with hemianopia. Consistently, they found a marked displacement towards the hemianopic side in line bisection tasks ${ }^{19-23} 29$ as well as in the calculated straight ahead position. ${ }^{27}$

A possible factor that may account for the discrepancies between the findings of Farnè et $a l^{17}$ and those of other studies, including the present one, concerns lesion sites. All patients with hemianopia investigated by Farnè et al had strokes in the territory of the middle cerebral artery affecting the parietal lobe in each case. It 
is thus possible that the opposing effects of a primary visual field defect and a lesion of the parietal lobe on an SSA task neutralised each other as found in the present study. To avoid such possible confounding effects of recovered or subtle hemineglect on an SSA localisation task, all cases of pure hemianopia in the present study were due to infarctions in the territory of the posterior artery. Lesions here are unlikely to evoke even subtle spatial neglect.

It has recently been discussed whether or not a displaced SSA perception is causally related to spatial neglect. Different aspects argue against such a relation. The present results indicate that SSA perception is not exclusively determined by those cortical lesions inducing spatial neglect. Perception of SSA was also affected by occipital lesions leading to hemianopia. A comparable finding was reported from patients with optic ataxia after superior parietal lobe lesions. ${ }^{16}$ These patients also displaced the SSA although they did not have spatial neglect. Thus, although several studies showed that spatial neglect seems to be highly correlated with a deviation of SSA, ${ }^{10-18}$ explicit determination of straight ahead body orientation by asking neglect patients to point the hand to $^{30}$ or to direct a target to "straight ahead" does not seem to be a specific measure for the deviation of egocentric space representation in these patients. A more valid measure of that deviation is required.

The common and most obvious clinical deficit of patients with neglect is that they do not explore the contralesional side of space and neglect objects located there. This deficit is specific for patients with neglect and is not seen in patients with pure hemianopia or in patients with pure optic ataxia. One tool to measure directly this exploration bias is recording the patients' exploratory movements-for example when searching for a certain target in space. Such registrations disclosed a deviated distribution of motor behaviour towards the ipsilesional side regardless of whether the patients explored space visually or by touch. ${ }^{31}{ }^{32}$

Determining the area of visual or tactile exploration along the horizontal dimension of space thus seems to be a more valid and direct measure characterising the deviated reference frame for space exploration in neglect patients. The centre of the explored area indicates the preferred orientation in space around which the patients execute their movements. This centre of exploration is shifted toward the ipsilesional side in patients with neglect whereas it corresponds with the body's midsagittal plane in other subjects. Compared with the recording of patients' exploration of space, measures such as pointing to or directing a single target to the SSA rather seem to rely on further cognitive processes besides the distribution of attention in space. By contrast with the biased exploration of space, ${ }^{31}{ }^{32}$ spatial neglect seems to be only one of several factors that (negatively) influence the processes contributing to SSA perception.

To conclude, the present study clearly showed that ipsilateral lesions of two different, anatomically separated cortical areas can both affect the SSA. Obviously, both the parietal and occipital cortex are involved in computing the perceived body orientation in the horizontal dimension.

We are grateful to Matthias Niemeier for assistance in the The work was supported by grant ka $1258 / 2-1$ from the DeutThe work was supported by grant ka $1258 / 2-1$ from
sche Forschungsgemeinschaft awarded to $\mathrm{H}-\mathrm{OK}$.

1 Werner H, Wapner S, Bruell JH. Experiments on sensorytonic field theory of perception: VI. Effect of position of head, eyes, and of object on position of the apparent median plane. F Exp Psychol 1953;42:346-50.

2 Jeannerod M, Biguer B. Référence égocentrique et espace représenté. Rev Neurol 1989;45:635-9.

3 Fischer MH, Kornmüller AE. Egozentrische Lokalisation. 2. Mitteilung (optische Richtungslosigkeit beim vesti2. Mitteilung (optische Richtungslosigkeit beim vest
bulären Nystagmus). F Psychol Neurol 1931;41:383-420.

bulären Nystagmus). $\mathcal{F}$ Psychol Neurol 1931;41:383-420.
4 Brecher GA, Brecher MH, Kommerell G, et al. Relation of Brecher GA, Brecher MH, Kommerell G, et al. Relation of
optical and labyrinthean orientation. Optica Acta 1972;19. $467-71$.

5 Hamann KF, Strauss K, Kellner M, et al. Dependence of visual straight ahead on vestibular influences. In: Krejcova $\mathrm{H}$, Jerabek J, eds. Proceedings of XVIIth Bárány Society Meeting. Castle Dobris, Czechoslovakia: Bárány Society, 1992:65-6.

6 Biguer B, Donaldson IML, Hein A, et al. Neck muscle vibration modifies the representation of visual motion and direction in man. Brain 1988;111:1405-24.

7 Karnath H-O, Sievering D, Fetter M. The interactive contribution of neck muscle proprioception and vestibular stimulation to subjective "straight ahead" orientation in man. Exp Brain Res 1994;101:140-6.

8 Grüsser O-J, Pause M, Schreiter U. Localization and responses of neurones in the parieto-insular vestibular cortex of awake monkeys (Macaca fascicularis). I Physiol (Lond) 1990;430:537-57.

9 Grüsser O-J, Pause M, Schreiter U. Vestibular neurones in the parieto-insular cortex of monkeys (Mcaca fascicularis): visual and neck receptor responses. F Physiol (Lond) 1990; 430:559-83.

10 Heilman KM, Bowers D, Watson RT. Performance on hemispatial pointing tasks by patients with neglect syndrome. Neurology 1983;33:661-4.

11 Mark VE, Heilman KM. Bodily neglect and orientational biases in unilateral neglect syndrome and normal subjects. Neurology 1990;40:640-3.

12 Karnath $\mathrm{H}-\mathrm{O}$. Subjective body orientation in neglect and the interactive contribution of neck muscle proprioception and vestibular stimulation. Brain 1994;117:1001-12.

13 Karnath H-O. Spatial orientation and the representation of space with parietal lobe lesions. Phil Trans $R$ Soc Lond $B$ 1997;352:1411-9.

14 Vallar G, Guariglia C, Nico D, et al. Spatial hemineglect in back space. Brain 1995;118:467-72

15 Chokron S, Imbert M. Variations of the egocentric reference among normal subjects and a patient with unilateral neglect. Neuropsychologia 1995;33:703-11.

16 Perenin MT. Optic ataxia and unilateral neglect: clinical evidence for dissociable spatial functions in posterior parietal cortex. In: P Thier, H-O Karnath, eds. Parietal lobe contributions to orientation in $3 D$ space. Heidelberg: Springer, 1997:289-308.

17 Farnè A, Ponti F, Làdavas E. In search of biased egocentric reference frames in neglect. Neuropsychologia 1998;36:61123.

18 Rossetti Y, Rode G, Pisella L, et al. Prism adaptation to a rightward optical deviation rehabilitates left hemispatial neglect. Nature 1998;395:166-9.

19 Axenfeld D. Eine einfache Methode Hemianopsie zu constatiren. Neurologisches Centralblatt 1894;13:437-38.

20 Liepmann H, Kalmus E. Ueber eine Augenmassstörung bei Hemianopikern. Berliner Klin Wochenschrift 1900;38:83842 .

21 Best F. Bemerkungen zur Hemianopsie. Graefes Arch Ophthalmol 1910;74:400-10.

22 Best F. Die Bedeutung der Hemianopsie für die Untersuchung des optischen Raumsinnes. Pflügers Archiv für die gesamte Physiologie 1910;136:248-62.

23 Strebel J. Uber Hemianopien. Archiv für Augenheilkunde 1924;94:27-55.

24 Fuchs W. Untersuchungen über das Sehen der Hemianopiker und Hemiamblyoniker: I. Verlagerungserscheinungen. $Z$ Psychol 1920;84:67-169.

25 Best F. Hemianopsie und Seelenblindheit bei Hirnverletzungen. Graefes Arch Ophthalmol 1917;93:49-150.

26 Kerkhoff G. Displacement of the egocentric visual midline in altitudinal postchiasmatic scotoma. Neuropsychologia 1993;31:261-5

27 Zihl J, v Cramon D. Zerebrale Sehstörungen. Stuttgart: Kohlhammer 1986:87-101.

28 Hasselbach M, Butter CM. Ipsilesional displacement of egocentric midline. In: $\mathrm{P}$ Thier, $\mathrm{H}-\mathrm{O}$ Karnath, eds. Parietal lobe contributions to orientation in $3 D$ space. Heidelberg: Springer, 1997:579-95. 
29 Barton JJS, Black SE. Line bisection in hemianopia. $7 \mathrm{Neu}-$ rol Neurosurg Psychiatry 1998;64:660-2.

rol Neurosurg Psychiatry 1998;64:660-2.
Chokron S, Bartolomeo P. Patterns of dissociation between left hemineglect and deviation of the egocentric reference. Neuropsychologia 1997;35:1503-8.

31 Karnath H-O, Perenin M-T. Tactile exploration of peripersonal space in patients with neglect. Neuroreport 1998;9: 2273-7.

32 Karnath H-O, Niemeier M, Dichgans J. Space exploration in neglect. Brain 1998;121:2357-67.
33 Bisiach E, Rusconi ML Break-down of perceptual awareness in unilateral neglect. Cortex 1990;26:643-9.

( The Tér R. The baking tray task: a test of spatial neglect. Neuropsychological Rehabilitation 1996;6:19-25.

35 Weintraub S, Mesulam M-M. Mental state assessment of young and elderly adults in behavioral neurology. In: Mesulam M-M, ed. Principles of behavioral neurology. Philadelphia: FA Davis, 1985.

36 Damasio H, Damasio AR. Lesion analysis in neuropsychology. Oxford: Oxford University Press, 1989.

\section{NEUROLOGICAL STAMP}

\section{Papyrus of Ebers and Smith}

Besides hieroglyphics usually engraved or painted on stone, the Egyptians employed certain cursive scripts, usually inscribed on thin sheets of the papyrus plant. The Ebers papyrus was advertised for sale in 1869 and obtained by Georg Ebers at Thebes in 1872. This dated back to about 1500 BC. The Edwin Smith papyrus is the oldest known medical writing and also the most complete and important treatise on the surgery of antiquity. It was written about $1700 \mathrm{BC}$ and thought to be a copy of a much more ancient manuscript written about 3000 BC, being more or less contemporaneous with the great pyramids. It was acquired at Luxor in 1862 and given to the New York Historical Society by Smith's daughter in 1906. Among the matters recorded in the document are head injuries and an incomplete account of sprain to the spinal column. In the case of depressed fracture of the skull, the need for removing the bony fragments with an elevator is stated. The author noted that paralysis of the bladder and of the intestines occurred with lesions of the spinal cord and paraplegia resulting from injury to the head varied depending on which side of the brain was injured. The brain with its convolutions and meninges is mentioned for the first time. The papyrus contains no clues as to the author's name.

Whereas the Edwin Smith papyrus is a surgical document, the papyrus of Ebers, by contrast, is medical. For the most part it contains a collection of recipes for

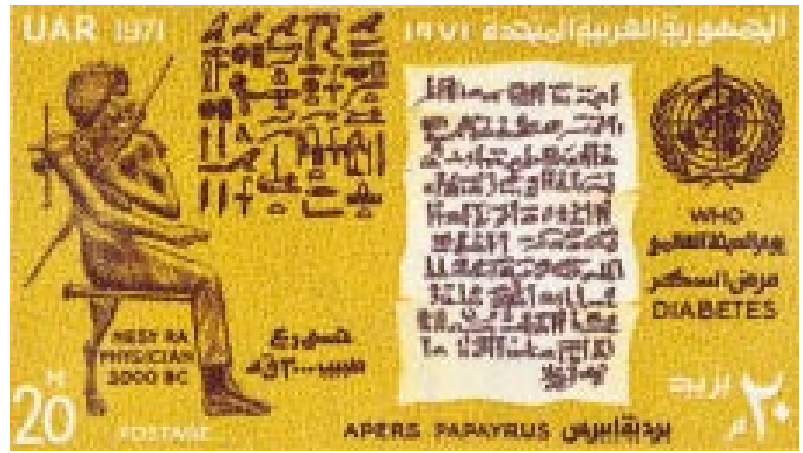

various diseases and symptoms. There are few descriptions of diseases. The writer notes three types of healers: physicians, surgeons, and sorcerers who are exorcists. Among the medicines mentioned in the papyrus of Ebers, ox liver against night blindness, powdered hyoscyamus to expel pain caused by worms, and a favourite Egyptian pomade for baldness consisting of equal parts of lion, hippopotamus, crocodile, goose, serpent, and ibex fats. Another consisted simply of equal parts of writing ink and CSF.

In 1971 Egypt published a stamp showing Hesy Ra (an ancient physician) and a papyrus (Stanley Gibbons 1098, Scott 864).

L F HAAS 